\title{
Prevalence and predictors of e-cigarette trial among adolescents in Argentina
}

\author{
Paola Morello', Adriana Perez", ${ }^{1,2}$ Lorena Peña', Paula Lozano ${ }^{3}$, James F. Thrasher ${ }^{3}$, James Sargent', Raul Mejía'
}

\begin{abstract}
INTRODUCTION Over the last few years, the increasing use of electronic cigarettes has become a new public health problem. Since 2011, Argentina has had a complete ban on marketing and sale of e-cigarettes. However, e-cigarettes are marketed online and can be easily bought in stores. We conducted a longitudinal study to evaluate the determinants of e-cigarette trial among Argentinean early adolescents.

METHODS A school-based longitudinal study was conducted in 2014-15, in 3 large cities in Argentina. Among students who reported never smoking an e-cigarette at baseline, we assessed demographics, media use, sensation seeking, smoking behavior, network member smoking, use of other substances, and perception of e-cigarette risk as potential risk factors for e-cigarette trial at follow up (mean between-wave interval 17.1 months) using multilevel logistic regression models with random intercepts for schools.

RESULTS E-cigarette trial prevalence increased from baseline $(1.8 \% ; \mathrm{n}=57)$ to follow up (7.1\%; $\mathrm{n}=139$ ). Independent predictors of e-cigarette use at follow up included: higher sensation seeking (OR: 1.49 95\% CI 1.21-1.84); being a current smoker (OR: 2.58 95\% CI 1.38-4.83); having close friends that smoke cigarettes (OR: 1.93 95\% CI 1.25-2.99) and being highly exposed to tobacco product ads online (OR: 1.87 95\% CI 1.04-3.36). Attending a public school was the only protective factor (OR: $0.4095 \%$ CI $0.22-0.73$ ).

CONCLUSION In Argentina, illicit trial of e-cigarettes among early adolescents is low but appears to be rapidly increasing. Identifying students at risk could help identify policies and programs to prevent increasing use in this population.
\end{abstract}

\author{
AFFILIATION \\ 1 Centro de Estudios de Estado \\ y Sociedad (CEDES), Argentina \\ 2 Facultad de Ciencias Exactas \\ y Naturales, Universidad de \\ Buenos Aires, Argentina \\ 3 Department of Health \\ Promotion, Education, and \\ Behavior University of South \\ Carolina, Columbia, USA \\ 4 Department of Pediatrics, \\ Geisel School of Medicine at \\ Dartmouth, USA
}

\section{KEYWORDS}

adolescents, school, e-cigarette, Public policy, adolescent health, Argentina

CORRESPONDENCE TO Paola Morello, Centro de Estudios de Estado y Sociedad (CEDES), Argentina, Sánchez de Bustamante 27, 1173 buenos aires, Argentina. Email: paolamorello@hotmail.com

\section{INTRODUCTION}

Tobacco use is a major concern and important policies and programmatic actions have been taken by most governments in order to reduce its use ${ }^{1}$. However, over the last few years, the increasing use of electronic cigarettes, commonly known as "e-cigarettes", has become a new public health problem that threatens to interfere with established tobacco control strategies. Several studies from developed countries show that e-cigarette use is increasing both in adults and adolescents ${ }^{2-5}$. Moreover, the potential for dual use of conventional cigarettes and e-cigarettes could undermine long term tobacco control efforts $^{6,7}$.

In Latin-America, a recent study in Mexico, where importation, marketing and sales of e-cigarettes is banned, found that half of Mexican secondary school students were aware of e-cigarettes and $10 \%$ had tried them ${ }^{8}$. Several cross-sectional and longitudinal studies have shown that trying an e-cigarette is associated with later cigarette use, suggesting that e-cigarettes could be a new gateway to tobacco use ${ }^{9-13}$. Although the relationship between initiation of e-cigarettes and of conventional cigarettes among early adolescents is likely bidirectional, only a few longitudinal studies have examined the factors that account for e-cigarette trial, including transitions from cigarette smoking to use of e-cigarettes or use of both types of nicotine delivery products ${ }^{3}$, $11,14,15$.

The correlates of trying e-cigarettes appear generally similar to those reported for cigarettes and can be divided 
into three mayor domains: sociodemographics (i.e., sex, age, parental education, type of school), personal risk (i.e., sensation seeking, prior cigarette use, other substance use) and network influences (i.e., friend smoking, household smoking and parenting style). Being male, having lower parental support, higher rebelliousness, peer tobacco use, and advertising exposures has been associated with trying an e-cigarette ${ }^{3,8,16-20}$. Alcohol and other drugs use have also been associated ${ }^{3,21}$. Beyond these more traditional risk factors for conventional cigarettes, the Mexican study indicated that trial of e-cigarettes was associated with more specific risk factors like greater utilization of electronic media devices (i.e., "technophilia"), bedroom Internet access, and Internet advertising exposures ${ }^{8}$. These risk factors may be particularly important in countries such as Argentina, that have banned e-cigarettes, as Internet can provide uncensored information including e-cigarette marketing.8.22. The perception than e-cigarettes are less harmful than regular tobacco has also been associated with increased risk of trial ${ }^{14,19}$.

The World Health Organization (WHO) recommends banning or restricting advertising, promotion and sponsorship of e-cigarettes ${ }^{23}$. Since 2011, Argentina has had a complete ban on marketing and sale of e-cigarettes ${ }^{24}$. However, e-cigarettes are marketed online and can be easily bought in stores for as low as 20 USD $^{25}$. To our knowledge, there are no current data on e-cigarette knowledge and use among youth in this country $^{26}$. We conducted a longitudinal study to evaluate the determinants of trying an e-cigarette among early adolescents in Argentina, in order to inform the development of prevention campaigns and further legislative efforts in this country.

\section{METHODS}

A school-based longitudinal study was conducted in 33 public and private schools from 3 of the largest cities in Argentina (Buenos Aires, Cordoba, and Tucuman). A sample of 18 public and 15 private secondary schools was purposively selected to capture the range of SES diversity. A detailed description of school selection has been published elsewhere ${ }^{27}$. Baseline surveys were administered between May and July 2014, among first year secondary school students. Passive consent from parents or caretakers and active consent from students was obtained before implementing the survey. An anonymous linking procedure was used to allow for follow-up ${ }^{28}$. Selfadministered surveys were completed in class under the supervision of trained research staff. The research protocol was approved by the human subjects' research board at the Centro de Educacion Médica e Investigaciones Clínicas (CEMIC) in Buenos Aires. Follow-up using the same survey was conducted between October and November 2015 (mean between-wave interval=17.1 months; range=16 to 19.3 months).

The survey included items previously used in Argentina, Mexico, and the US, which were pretested to ensure understanding of questions, instructions and confidentiality statements ${ }^{29-31}$. Very few changes to the original survey were made after we reviewed the student's suggestions.

\section{Measurement}

The primary dependent variable for this study was trial of e-cigarettes and was assessed by asking: "Have you ever tried an e-cigarette?" (yes, no) at both baseline and follow up.

Independent variables were assessed at baseline and included a range of sociodemographic variables: age, sex, type of school (public vs private) and educational attainment of parents (i.e., highest level reported for either parent). Sensation-seeking was assessed with four items ("I like to do scary things"; "I like to explore strange places"; "I like new and exciting experiences, even if I have to break the rules"; "Sometimes I do 'crazy' just for fun", with Likert scale responses ${ }^{32}$. Because internal consistency was high (alpha $=0.79$ ), these were averaged with higher scores indicating higher sensation seeking tendencies. Parenting behavior was assessed with questions on responsiveness and demandingness from Jackson's Authoritative Parenting Index, using three items for each parenting dimension and for each parent. Scores were averaged for both parents Scores for both dimensions were combined, with higher scores indicating more authoritative parenting, which has been associated with lower likelihood of substance use, including smoking". (alpha $=0.86$ for mother; alpha $=0.80$ for father $)^{33}$. Substance use was assessed (prior 30 day use of cigarettes; prior 30 day use of alcohol; lifetime use of marijuana or cocaine), as well as smoking among network members (i.e., any of five closest friends; any household member). Perceptions of e-cigarette risks were assessed by combining questions about awareness of e-cigarettes and perceived risk compared to regular cigarettes, resulting in the following three categories: 1 . aware of e-cigarettes and thinks they are equally or more harmful than cigarettes; 2 . aware and thinks they are less harmful than regular cigarettes; 3 . unaware or e-cigarettes or does not know the relative risk. Media-related variables related included a technophilia index previously used in Mexico (i.e., summing use of smartphone, tablet, and computer; range 0-3), whether the student had Internet access in his/her bedroom and frequency of seeing ads for tobacco products on the internet ("never," "rarely," "sometimes," "most of the time," "always," with the last two combined for "high") ${ }^{6}$. 


\section{Analysis}

Analyses were conducted using Stata version v13 (Stata Corp, College Station, TX). First, in an attrition analysis, we examined the distribution of the variables to assess differences between students who were and were not followed-up using chi-square and $\mathrm{t}$ tests. The dependent variable question described above was used to assess trying e-cigarettes in all students who completed the baseline survey $(n=3172)$ and the follow-up survey $(n=2018)$. To assess the variables that predict new onset of e-cigarette use, we limited the sample for the multivariable analysis to those students who had never tried an e-cigarette at baseline and who had completed both baseline and follow up surveys (i.e., $n=1976$; 64\% follow up). Multilevel logistic regression models with random intercepts for school were used to assess the association between independent variables and new onset of trying e-cigarettes by the follow-up survey. Models were adjusted adding groups of variables that reflected the domains of the conceptual model. To account for potential attrition bias, we estimated weights to apply to each observation in models of e-cigarettes use. Weighting had little effect on most estimates of OR and, as such, we decided to present the non-weighted results.

\section{RESULTS}

Overall, 3172 students (participation rate 83\%) completed the survey at baseline and 3059 had not tried an e-cigarette $(42.7 \%$ female) with a mean age of 12.8. Of those, 2018 students also completed the follow up survey. At baseline, 57 (1.8\%) had tried an e-cigarette and, among those who completed both surveys, 151 (7.6\%) had tried one at follow up. Among those who had not smoked e-cigarettes at baseline, 7\% had tried e-cigarettes by follow-up.

Table 1 shows the baseline characteristics of all the students who completed the baseline survey and had not tried an e-cigarette and among those, the characteristics of the students who completed the follow up survey and of those who didn't. Compared to those who completed both surveys, adolescents lost to follow up were more likely to be male, older, to attend a public school and have less-well educated parents, to have more household or friends who smoke, to be current smokers and to have higher sensation seeking tendencies.

At baseline, there were 111 students who were current smokers and had not tried an e-cigarette. Of those, 19 had tried an e-cigarette by follow-up (17.1\%), among whom $63.2 \%$ (12/19) were still current smokers and 36.8\% (7/19) reported no current smoking at follow-up. Of the 92 baseline smokers who did not try an e-cigarette at follow-up, 51/92 (55.4\%) were still current smokers and 41/92 (44.6\%) reported no current smoking at follow-up.

In bivariate analyses (Table 2), e-cigarette initiation was associated with baseline substance use: current smoking (OR: 5.00 95\% CI 2.75-9.09); current drinking (OR: 2.57 95\% CI 1.71-3.84); and having ever used drugs (OR: 4.66 95\% CI 2.44-8.90). After we introduced each domain, the predictors of trying e-cigarettes did no vary. Those who were statistically significant were: higher sensation seeking (OR: 1.46 95\% CI 1.18-1.81), being a current smoker (OR: 2.58 95\% CI 1.384.83), having friends who smoke conventional cigarettes (OR:

Table 1 Characteristics of all the students who had not tried ane cigarette at baseline, those who completed baseline and follow up survey and those lost to follow up.

\begin{tabular}{|c|c|c|c|c|}
\hline Variables & e-cigarette & $\begin{array}{c}\text { Students who had not tried ane- } \\
\text { cigaret te at baseline and completed } \\
\text { Follow upsurvey }\end{array}$ & $\begin{array}{l}\text { Students who had not tried ane } \\
\text { cigarette at baseline and did not } \\
\text { complete Follow upsurvey }\end{array}$ & $P^{*}$ \\
\hline & $n=3059$ & $\begin{array}{l}n=1976 \\
(64.2 \%)\end{array}$ & $\begin{array}{l}n=1100 \\
(35.8 \%)\end{array}$ & \\
\hline \multicolumn{5}{|c|}{ Sociodemographic } \\
\hline Sex (girl) & 1307 (42.7\%) & $891(45.4 \%)$ & $416(38 \%)$ & 0.001 \\
\hline $\begin{array}{l}\text { Age (years) } \\
\text { mean (SD) }\end{array}$ & $12.82(.94)$ & $12.66(0.84)$ & $13.10(1.05)$ & 0.001 \\
\hline $\begin{array}{l}\text { Type of school } \\
\text { (public) }\end{array}$ & 2087 (67.7\%) & $1224(61.9 \%)$ & $863(78.5 \%)$ & 0.001 \\
\hline \multicolumn{5}{|c|}{ Parental education } \\
\hline $\begin{array}{l}\text { Primary in/ } \\
\text { complete }\end{array}$ & $209(6.9 \%)$ & $114(5.9 \%)$ & $95(8.8 \%)$ & 0.001 \\
\hline $\begin{array}{l}\text { Secondary in/ } \\
\text { complete }\end{array}$ & $1246(41.2 \%)$ & $795(41 \%)$ & $451(41.7 \%)$ & \\
\hline Terciary or more & $1259(41.6 \%)$ & $859(44.3 \%)$ & $400(37 \%)$ & \\
\hline $\begin{array}{l}\text { Unknown } \\
\text { education }\end{array}$ & $309(10.2 \%)$ & $173(8.9 \%)$ & $136(12.6 \%)$ & \\
\hline
\end{tabular}




\begin{tabular}{|c|c|c|c|c|}
\hline \multicolumn{5}{|c|}{ Network influences } \\
\hline Friends smoking & $1289(42.1 \%)$ & $703(35.7 \%)$ & $586(53.6 \%)$ & 0.001 \\
\hline $\begin{array}{l}\text { Household } \\
\text { smoking }\end{array}$ & $1688(55.3 \%)$ & $1073(51.6 \%)$ & $675(61.9 \%)$ & 0.001 \\
\hline $\begin{array}{l}\text { Parenting style } \\
\text { index (1-5) } \\
\text { mean (SD) }\end{array}$ & $3.98(0,77)$ & $4.03(0.72)$ & $3.89(0.83)$ & 0.001 \\
\hline \multicolumn{5}{|c|}{ General Risk Factors } \\
\hline $\begin{array}{l}\text { Current tobacco } \\
\text { use }\end{array}$ & $280(9.1 \%)$ & $111(9.1 \%)$ & $169(15.4 \%)$ & 0.001 \\
\hline $\begin{array}{l}\text { Current alcohol } \\
\text { use }\end{array}$ & $750(24.5 \%)$ & $384(19.5 \%)$ & $366(33.4 \%)$ & 0.001 \\
\hline $\begin{array}{l}\text { Lifetime drug } \\
\text { use }\end{array}$ & $222(7.2 \%)$ & $77(3.9 \%)$ & $145(13.2 \%)$ & 0.001 \\
\hline $\begin{array}{l}\text { Sensation } \\
\text { seeking index } \\
(1-5) \text { mean } \\
\text { (SD) }\end{array}$ & $3.20(1.06)$ & $3.12(1.04)$ & $3.33(1.07)$ & 0.001 \\
\hline \multicolumn{5}{|c|}{ Specific risk factors } \\
\hline $\begin{array}{l}\text { Technophilia } \\
(0-3) \text { mean } \\
\text { (SD) }\end{array}$ & $1.85(.86)$ & $1.82(.85)$ & $1.89(.86)$ & 0.03 \\
\hline Internet access & 2487 (82.4\%) & $1610(83.1 \%)$ & $877(81.2 \%)$ & 0.19 \\
\hline \multicolumn{5}{|l|}{ Ads online } \\
\hline never & $977(32 \%)$ & $617(31.5 \%)$ & $360(33 \%)$ & 0.019 \\
\hline sometimes & $736(24.1 \%)$ & $1104(54.6 \%)$ & $567(51.9 \%)$ & \\
\hline $\begin{array}{l}\text { most times / } \\
\text { always }\end{array}$ & $1138(43.9 \%)$ & $238(12.1 \%)$ & $165(15.1 \%)$ & \\
\hline \multicolumn{5}{|c|}{ Awareness and perceived risks of e-cigarettes } \\
\hline $\begin{array}{l}\text { Unaware or } \\
\text { aware not know } \\
\text { risk }\end{array}$ & $2692(86 \%)$ & $1685(85 \%)$ & $944(86.4 \%)$ & 0.192 \\
\hline Aware equal risk & $242(7.9 \%)$ & $149(7.5 \%)$ & $93(8.5 \%)$ & \\
\hline Aware less risk & $186(6 \%)$ & $130(6.5 \%)$ & $56(3.1 \%)$ & \\
\hline
\end{tabular}

*t-test for continuous variables and chi-square test for categorical variables comparing students that were follow up and those who were not. SD Standard Deviation

Table 2 Crude and adjusted odds ratios (AOR) of trying an e-cigarette according to different models

\begin{tabular}{|c|c|c|c|c|c|c|}
\hline VARIABLES & $\begin{array}{l}\text { Crude OR } \\
(95 \% \mathrm{CI})\end{array}$ & $\begin{array}{c}\text { Model I } \\
\text { AOR }(95 \% \mathrm{CI})\end{array}$ & $\begin{array}{c}\text { Model } 2 \\
\text { AOR }\left(95^{\circ} \% \mathrm{CI}\right)\end{array}$ & $\begin{array}{c}\text { Model } 3 \\
\text { AOR }(95 \% \mathrm{CI})\end{array}$ & $\begin{array}{c}\text { Model } 4 \\
\text { AOR }(95 \% \text { CI })\end{array}$ & $\begin{array}{c}\text { Model } 5 \\
\text { AOR }(95 \% \mathrm{CI})\end{array}$ \\
\hline \multicolumn{7}{|c|}{ Sociodemographic } \\
\hline Girl & $\begin{array}{c}0.84 \\
(0.57-1.22)\end{array}$ & $\begin{array}{c}0.80 \\
(0.54-1.18)\end{array}$ & $\begin{array}{c}0.80 \\
(0.54-1.18)\end{array}$ & $\begin{array}{c}0.89 \\
(0.60-1.33)\end{array}$ & $\begin{array}{c}0.90 \\
(0.60-1.35)\end{array}$ & $\begin{array}{c}0.97 \\
(0.64-1.46)\end{array}$ \\
\hline Age & $\begin{array}{c}0.84 \\
(0.62-1.14)\end{array}$ & $\begin{array}{c}0.92 \\
(0.68-1.26)\end{array}$ & $\begin{array}{c}0.86 \\
(0.63-1.16)\end{array}$ & $\begin{array}{c}0.79 \\
(0.58-1.08)\end{array}$ & $\begin{array}{c}0.81 \\
(0.59-1.11)\end{array}$ & $\begin{array}{c}0.79 \\
(0.57-1.09)\end{array}$ \\
\hline Public school & $\begin{array}{c}0.42^{* *} \\
(0.25-0.71)\end{array}$ & $\begin{array}{c}0.44^{* *} \\
(0.24-0.78)\end{array}$ & $\begin{array}{c}0.36^{* * *} \\
(0.22-0.73)\end{array}$ & $\begin{array}{c}0.38^{* *} \\
(0.22-0.68)\end{array}$ & $\begin{array}{c}0.39^{* *} \\
(0.22-0.70)\end{array}$ & $\begin{array}{c}0.41^{* *} \\
(0.23-0.75)\end{array}$ \\
\hline $\begin{array}{l}\text { Parental education } \\
\text { Secondary in/complete }\end{array}$ & $\begin{array}{c}1.57 \\
(0.61-4.07)\end{array}$ & $\begin{array}{c}1.47 \\
(0.57-3.82)\end{array}$ & $\begin{array}{c}1.32 \\
(0.51-3.46)\end{array}$ & $\begin{array}{c}1.37 \\
(0.52-3.62)\end{array}$ & $\begin{array}{c}1.35 \\
(0.51-3.59)\end{array}$ & $\begin{array}{c}1.38 \\
(0.52-3.68)\end{array}$ \\
\hline Terciary or more & $\begin{array}{c}1.47 \\
(0.56-3.85)\end{array}$ & $\begin{array}{c}1.26 \\
(0.48-3.29)\end{array}$ & $\begin{array}{l}1.25(0.47- \\
3.28)\end{array}$ & $\begin{array}{c}1.31 \\
(0.49-3.51)\end{array}$ & $\begin{array}{c}1.27 \\
(0.47-3.42)\end{array}$ & $\begin{array}{c}1.25 \\
(0.46-3.38)\end{array}$ \\
\hline Unknown education & $\begin{array}{c}1.18 \\
(0.39-3.63)\end{array}$ & $\begin{array}{c}1.15 \\
(0.39-3.63)\end{array}$ & $\begin{array}{c}1.13 \\
(0.37-3.51)\end{array}$ & $\begin{array}{c}1.17 \\
(0.37-3.69)\end{array}$ & $\begin{array}{c}1.15 \\
(0.36-3.7)\end{array}$ & $\begin{array}{c}1.18 \\
(0.36-3.82)\end{array}$ \\
\hline \multicolumn{7}{|c|}{ Network influences } \\
\hline Friends smoking & $\begin{array}{c}2.17^{* * *} \\
(1.48-3.18)\end{array}$ & & $\begin{array}{c}2.44^{* * *} \\
(1.64-3.64)\end{array}$ & $\begin{array}{c}1.89^{* *} \\
(1.24-2.89)\end{array}$ & $\begin{array}{c}1.79^{* *} \\
(1.16-2.77)\end{array}$ & $\begin{array}{c}1.82^{* *} \\
(1.25-2.99)\end{array}$ \\
\hline
\end{tabular}




\begin{tabular}{|c|c|c|c|c|c|}
\hline Household smoking & $\begin{array}{c}1.48^{*} \\
(1.03-2.13)\end{array}$ & $\begin{array}{c}1.44 \\
(.98-2.11)\end{array}$ & $\begin{array}{c}1.33 \\
(.90-1.96)\end{array}$ & $\begin{array}{c}1.39 \\
(0.93-2.06)\end{array}$ & $\begin{array}{c}1.36 \\
(0.91-2.03)\end{array}$ \\
\hline Parenting style index & $\begin{array}{c}0.90 \\
(0.70-1.15)\end{array}$ & $\begin{array}{c}0.95 \\
(0.73-1.23)\end{array}$ & $\begin{array}{c}1.03 \\
(0.78-1.34)\end{array}$ & $\begin{array}{c}1.03 \\
(0.78-1.36)\end{array}$ & $\begin{array}{c}1.04 \\
(0.79-1.38)\end{array}$ \\
\hline \multicolumn{6}{|c|}{ General Risk factors } \\
\hline Current tobacco use & $\begin{array}{c}5.00 * * * \\
(2.75-9.09)\end{array}$ & & $\begin{array}{c}2.61^{* *} \\
(1.40-4.85)\end{array}$ & $\begin{array}{c}2.49^{* *} \\
(1.33-4.67)\end{array}$ & $\begin{array}{c}2.58^{* *} \\
(1.38-4.83)\end{array}$ \\
\hline Current alcohol use & $\begin{array}{c}2.57^{* * *} \\
(1.71-3.84)\end{array}$ & & & & \\
\hline Lifetime Drug use & $\begin{array}{c}4.66^{* * *} \\
(2.44-8.90)\end{array}$ & & & & \\
\hline Sensation seeking index & $\begin{array}{c}1.64^{* * *} \\
(1.36-1.99)\end{array}$ & & $\begin{array}{c}1.49^{* * *} \\
(1.21-1.82)\end{array}$ & $\begin{array}{c}1.46^{* * *} \\
(1.18-1.80)\end{array}$ & $\begin{array}{c}1.46^{* * *} \\
(1.18-1.81)\end{array}$ \\
\hline \multicolumn{6}{|c|}{ Specific risk factors } \\
\hline Technofilia & $\begin{array}{c}1.08 \\
(0.87-1.33)\end{array}$ & & & $\begin{array}{c}0.92(0.72- \\
1.19)\end{array}$ & $\begin{array}{c}0.93 \\
(0.72-1.20)\end{array}$ \\
\hline $\begin{array}{l}\text { Internet Access in } \\
\text { bedroom }\end{array}$ & $\begin{array}{c}1.52 \\
(0.88-2.60)\end{array}$ & & & $\begin{array}{l}1.22(0.67- \\
2.23)\end{array}$ & $\begin{array}{c}1.22 \\
(0.67-2.24)\end{array}$ \\
\hline \multicolumn{6}{|l|}{ Ads online } \\
\hline rarely/sometimes & $\begin{array}{c}1.53 \\
(0.98-2.38)\end{array}$ & & & $\begin{array}{c}1.20 \\
(0.75-1.93)\end{array}$ & $\begin{array}{c}1.15 \\
(0.71-1.86)\end{array}$ \\
\hline most times /always & $\begin{array}{c}2.96^{* * *} \\
(1.73-5.05)\end{array}$ & & & $\begin{array}{c}1.92^{*} \\
(1.07-3.45)\end{array}$ & $\begin{array}{c}1.87^{*} \\
(1.04-3.36)\end{array}$ \\
\hline \multicolumn{6}{|c|}{ Awareness and perceived risks of e-cigarettes } \\
\hline $\begin{array}{l}\text { Aware and perceive as } \\
\text { less risky }\end{array}$ & $\begin{array}{c}1.89 \\
(0.86-4.18)\end{array}$ & & & & $\begin{array}{c}1.70 \\
(0.71-4.09)\end{array}$ \\
\hline $\begin{array}{l}\text { Unaware or do not } \\
\text { know risk }\end{array}$ & $\begin{array}{c}0.70 \\
(0.38-1.30)\end{array}$ & & & & $\begin{array}{c}0.83 \\
(0.43-1.61)\end{array}$ \\
\hline
\end{tabular}

1.82 95\% CI 1.25-2.99), and reporting higher exposure to ads for tobacco products online (OR: 1.87 95\% CI 1.04 - 3.36). Attending a public school was the only protective factor for trying an e-cigarette (OR: 0.41 95\% CI 0.23-0.75).

\section{DISCUSSION}

Our study found that, in this cohort of early adolescents who live in a country that bans e-cigarettes, the trial of e-cigarettes increased from $1.8 \%$ to $7.6 \%$ over a 17 month period. Trial of an e-cigarette was associated with prior use of traditional cigarettes, higher sensation seeking, having friends who smoke cigarettes and greater exposure to tobacco product ads online. This study is consistent with studies from other countries like New Zealand, the US, Finland and Poland, where the prevalence of trying an e-cigarette (although higher in these countries) increased by follow-up. ${ }^{3,5,15,34}$. While the e-cigarette ban in Argentina may help explain the somewhat lower prevalence we found, our sample of early adolescents was substantially younger (mean age $=12.5$ at baseline) than samples in other studies ${ }^{3,4,9,11,34}$. Almost one in five students who were current smokers and had not tried an e-cigarette at baseline tried an e-cigarette at follow-up, and among them $63.4 \%$ had continued to smoke regular cigarettes (dual use). This raises the concern that young students who are already smoking regular cigarettes are trying/using multiple nicotine delivery products. The possibility that some of them are using e-cigarettes as a harm reduction strategy or to quit smoking as amongst adults should be explored in future studies. The only other longitudinal study among early adolescents also found an association between use of conventional cigarettes at baseline and e-cigarette use at follow-up ${ }^{12}$.

Results from cross-sectional studies in other populations show that e-cigarette initiation is associated with being male, older, having parents with lower educational attainment and perceiving e-cigarettes are safer than conventional cigarettes $^{4,7,14,15,16,18}$. Results from our study suggest that smoking by close friends and sensation seeking are risk factors for trying e-cigarettes among Argentinean adolescents. Similar results were found among German adolescents and adolescents from New Zealand suggesting that these risk factors may generalize across sociocultural and regulatory contexts $^{3,15}$. In our study, however, none of the other variables 
were associated with trying an e-cigarette.

In this study attending a public school, which typically enrolls students from lower socioeconomic groups (SES) than private schools, was a protective factor for trying an e-cigarette at follow-up. The average price of an e-cigarette in Argentina is 600 ARS (about $\$ 40$ USD) ${ }^{25}$. Considering that this is about $8 \%$ of the minimum wage in the country, it is not surprising that students from relatively lower SES groups have less access to e-cigarettes. Prior research on how e-cigarette initiation is shaped by SES is somewhat inconsistent with our findings. How SES influences tobacco use is likely to be a complex process, and factors like the stage of the tobacco epidemic may matter, since smoking generally becomes more highly concentrated in lower SES groups as the epidemic progresses $^{35}$. Nevertheless, some potential markers of SES that were associated with e-cigarette use in Mexico, such as "technophilia" (greater access to technology) and internet access, were unassociated with e-cigarette use in our study ${ }^{6}$. This contrary finding may be due to the Mexican study taking place only amongst public school children, where these factors may matter more for e-cigarette use than more socioeconomically advantaged students who are more likely to attend private school.

Baseline awareness of e-cigarettes or their relative risk compared to conventional cigarettes did not predict e-cigarette smoking initiation in our study, which is inconsistent with prior longitudinal research ${ }^{11}$. Perhaps unsurprisingly given the regulatory context and the age of the sample, $85 \%$ of students were unaware of e-cigarettes or their relative risk at baseline, which is very low compared to other studies ${ }^{14,15,16,36,37}$. Communication campaign on the risks of e-cigarette use may be necessary to raise awareness of e-cigarette risks and thereby prevent their use.

Importation, distribution, sales and marketing of e-cigarettes are banned in Argentina since 2011, which should limit access to e-cigarettes for early adolescent $\mathrm{s}^{24}$. However, several webpages (i.e. http://solovapeamos.com/) and kiosks where regular cigarettes are sold and other general stores also sell them. A recent article in one of the main local newspapers shows that retailers reported a large increase in sales over the last year, particularly among young adults who find it "trendy and cool"(Diario La Nacion) ${ }^{25}$. The fact that trial of e-cigarettes appears to be rapidly increasing among early adolescents is a clear sign that the Government should implement an effective strategy to enforce existing legislation.

This study has several limitations that should be acknowledged. Compared to students who were followed up, those lost to follow-up were more likely to have a range of risk factors for cigarette and e-cigarette use, such as higher sensation seeking and use of a variety of substances. Hence, we may have underestimated the prevalence of e-cigarette trial in this population. Furthermore, due to maturation effects, trial of e-cigarettes within a cohort can only go up over time. Future research should assess the extent of population-level changes in trial and more intensive use of e-cigarettes over time. Schools were not randomly selected and the sample of schools may not be representative of the general population in Argentina. However, schools were selected to represent the range of socioeconomic diversity in three large cities, suggesting that the results might be similar to those for urban Argentine populations. Also, several studies have tested whether the use of e-cigarettes increases the risk for transition to combustible products, ${ }^{911}$. E-cigarette experimentation in our initial sample was too low to allow us to study the transition from e-cigarette use only to regular tobacco use; a new study with the specific objective of testing the transition in this population should be implemented to have local data. Also, using a larger population or improved follow-up strategy may help to reach sufficient sample sizes to test this transition.

\section{CONCLUSION}

This study finds that trial of e-cigarettes exists among Argentinean early adolescents, in spite of e-cigarette marketing and sales bans. The trial of e-cigarettes is increasingly common. Identifying students from private schools who are current smokers, have friends who smoke, have high exposure to tobacco products online and have a high sensation seeking index might help preventing increasing use in this population.

\section{REFERENCES}

1. WHO report on the global tobacco epidemic, 2015: raising taxes on tobacco. World Health Organization, Geneva. 2015 Available at: http://www.who.int/tobacco/global_report/2015/report/en/ (accessed April 2016)

2. Gravely S, Fong GT, Cummings KM, et al. Awareness, trial, and current use of electronic cigarettes in 10 countries: Findings from the ITC project. Int J Environ Res Public Health 2014;11(11):11691-704. doi: 10.3390/ijerph111111691

3. White J, Li J, Newcombe R, et al. Tripling use of electronic cigarettes among New Zealand adolescents between 2012 and 2014. J Adolesc Health 2015;56(5):522-528.

doi: 10.1016/j.jadohealth.2015.01.022

4. Babineau K, Taylor K, Clancy L. Electronic Cigarette Use among Irish Youth: A Cross Sectional Study of Prevalence and Associated Factors. Plos One 2015;10(5):e0126419. doi: $0.1371 /$ journal.pone.0126419

5. Singh T, Arrazola RA, Corey CG, et al. Tobacco Use Among Middle and High School Students — United States, 2011-2015. MMWR Morb Mortal Wkly Rep 2016;65:361-367. doi: http://dx.doi.org/10.15585/mmwr.mm6514a1 
6. Goniewicz ML, Leigh NJ, Gawron M, et al. Dual use of electronic and tobacco cigarettes among adolescents: a cross-sectional study in Poland. Int J Public Health. 2016;61(2):189-97. doi: 10.1007/s00038-015-0756-x

7. Land S, Parascandola M, et al. Tobacco use transitions in the United States: The National Longitudinal Study of Adolescent Health. Prev Med. 2015;81:251-7. doi: 10.1016/j.ypmed.2015.08.026.

8. Thrasher JF, Abad-Vivero EN, Barrientos-Gutíerrez I, et al. Prevalence and Correlates of E-Cigarette Perceptions and Trial Among Early Adolescents in Mexico. J Adolesc Health. 2016;58(3):358-65. doi: 10.1016/j.jadohealth.2015.11.008

9. Bunnell RE, Agaku IT, Arrazola RA, et al. Intentions to smoke cigarettes among never-smoking US middle and high school electronic cigarette users: National Youth Tobacco Survey, 20112013. Nicotine Tob Res. 2015;17(2): 228-235. doi: 10.1093/ntr/ntu166.

10. Wills TA, Sargent JD, Knight R, et al. E-cigarette use and willingness to smoke: a sample of adolescent non-smokers. Tob Control. 2016;25(e1):e52-9. doi: 10.1136/tobaccocontrol-2015-052349.

11. Primack BA, Soneji S, Stoolmiller M, et al. Progression to Traditional Cigarette Smoking After Electronic Cigarette Use Among US Adolescents and Young Adults. JAMA Pediatr 2015;169(11):1018-23.

doi: 10.1001/jamapediatrics.2015.1742

12. Leventhal AM, Strong DR, Kirkpatrick MG, et al. Association of Electronic Cigarette Use With Initiation of Combustible Tobacco Product Smoking in Early Adolescence. JAMA. 2015;314(7):700-7. doi: 10.1001/jama.2015.8950

13. Chatterjee K, Alzghoul B, Innabi A, Meena N. Is vaping a gateway to smoking: a review of the longitudinal studies. Int J Adolesc Med Health. 2016. pii: /j/ijamh.ahead-of-print/ijamh-2016-0033/ ijamh-2016-0033.xml. doi: 10.1515/ijamh-2016-0033.

14. Choi K, Forster JL Beliefs and experimentation with electronic cigarettes: a prospective analysis among young adults. Am J Prev Med 2014;46:175-8.

doi: 10.1016/j.amepre.2013.10.007

15. Hanewinkel R, Isensee B Risk factors for e-cigarette, conventional cigarette, and dual use in German adolescents: a cohort study. Prev Med 2015;74:59-62.

doi: 10.1016/j.ypmed.2015.03.006

16. Pokhrel P, Fagan P, Kehl L, et al. Receptivity to e-cigarette marketing, harm perceptions, and e-cigarette use. Am J Health Behav. 2015;39(1):121-31. doi: 10.5993/AJHB.39.1.13

17. Kinnunen JM, Ollila H, El-Amin SE-T, et al. Awareness and determinants of electronic cigarette use among Finnish adolescents in 2013: a population-based study. Tob Control 2014:1-8. doi: 10.1136/tobaccocontrol-2013-051512

18. Ambrose BK, Rostron BL, Johnson et al. Perceptions of the Relative Harm of Cigarettes and E-cigarettes Among U.S. Youth. Am J Prev Med 2014;47:S53-S60.

doi: 10.1016/j.amepre.2014.04.016

19. Wills TA, Knight R, Sargent JD, et al. Longitudinal study of e-cigarette use and onset of cigarette smoking among high school students in Hawaii. Tob Control. 2016 Jan 25. pii: tobaccocontrol-2015-052705. doi: 10.1136/tobaccocontrol-2015-052705.

20. Kong G, Morean ME, Cavallo DA, et al. Reasons for electronic cigarette experimentation and discontinuation among adolescents and young adults. Nicotine Tob Res 2015;17(7):847-54 doi: 10.1093/ntr/ntu257.

21. Dautzenberg B, Birkui P, Noël M, Dorsett J,et. al E-Cigarette: A New Tobacco Product for Schoolchildren in Paris. Open Journal of Respiratory Diseases, 2013, 3, 21-24 doi: 10.4236/ojrd.2013.31004

22. Huang GC, Unger JB, Soto D, et al. Peer Influences: The Impact of Online and Offline Friendship Networks on Adolescent Smoking and Alcohol Use. J Adoles Health., 2014;54(5):508-14. doi: $10.1016 /$

23. WHO Electronic nicotine delivery systems.2014. FCTC/CO

24. ANMAT Disposicion 3226/2011. Available at: http://www.msal. gob.ar/tabaco/index.php/institucional/legislacion (accessed April 2016)

25. Melamed M. La zona gris del cigarrillo electronico: esta prohibido, pero igual se vende en el país. Diario La Nacion. Available at: http://www.lanacion.com.ar/1887558-vaping-la-zona-gris-delcigarrillo-electronico (accessed April 2016)

26. Ministerio de Salud de la Nacion. Encuesta Mundial de Tabaquismo en jovenes (EMTJ). Argentina: 2012. Available at: http://www. msal.gov.ar/ent/index.php/vigilancia/publicaciones/encuestaspoblacionales (accessed July 2016)

27. Mejia R, Perez A, Pena L, Morello P, et al. Parental Restriction of Mature-rated Media and Its Association With Substance Use Among Argentinean Adolescents. Acad Pediatr. 2016;16(3):282-9. doi: 10.1016/j.acap.2015.11.004

28. Galanti MR, Siliquini R, Cuomo L, et al. \& EU-Dap Study Group. Testing anonymous link procedures for follow-up of adolescents in a school-based trial: the EU-DAP pilot study. 2007.Prev Med;44(2), 174-17

29. Alderete E, Kaplan C P, Gregorich SE, et al. Smoking behavior and ethnicity in Jujuy, Argentina: evidence from a low-income youth sample. 2009. Subst Use Misuse;44(5), 632-646. doi: 10.1080/10826080902809717.

30. Thrasher J F, Jackson C, ArilloSantillan E, Sargent JD. Exposure to smoking imagery in popular films and adolescent smoking in Mexico. 2008. Am J Prev Med;35(2):95102.

doi: 10.1016/j.amepre.2008.03.036

31. Sargent J D, Beach M L, AdachiMejia A M et al. Exposure to movie smoking: its relation to smoking initiation among US adolescents. 2005. Pediatrics, 116(5), 1183-91

32. Stephenson MT, Hoyle RH, Palmgreen P, Slater MD. Brief measures of sensation seeking for screening and large-scale surveys. 2003. Drug Alcohol depend;72(3):279-286.

33. Jackson C, Henriksen 1, FosheeVA. The Authoritative Parenting Index: predicting health risk behaviors among children and adolescents. Health Educ Behav. 1998; 258(3):319-337

34. Goniewicz ML, Gawron M, Nadolska J, et al. Rise in electronic cigarette use among adolescents in Poland. J Adolesc Health 2014;55:713-15.
CONFLICT OF INTEREST The authors have completed and submitted the ICMJE Form for Disclosure of Potential Conflicts of Interest and none were reported.

\section{FUNDING}

This work was supported by the National Cancer Institute and the Fogarty International Center of the National Institutes of Health under award numbers TWO09274 (MPI Sargent \& Thrasher) and CA077026 (PI Sargent). The content is solely the responsibility of the authors and does not necessarily represent the official views of the National Institutes of Health REVIEW

Not commissioned; externally peer reviewed
PROVENANCE AND PEER 


\section{Research Paper}

doi: 10.1016/j.jadohealth.2014.07.015

35. Hanson MD, Chen E. Socioeconomic status and health behaviors in adolescence: a review of the literature. Journal of behavioral medicine 2007;30(3):263-85

36. Choi K, Forster J. Characteristics associated with awareness, perceptions, and use of electronic nicotine delivery systems among young US Midwestern adults. Am J Public Health. 2013;103(3):556-61.

doi: 10.1016/j.amepre.2013.10.007.

37. Wills TA, Knight R, Williams R, et al. Risk factors for exclusive e-cigarette use and dual e-cigarette and tobacco use in adolescents. Pediatrics 2015;135:e43-51.

doi: 10.1542/peds.2014-0760 